\title{
MORTALITY FROM CANCER ACCORDING TO SITE IN THE COUNTIES OF SCOTLAND, 1923-8.
}

\author{
By W. T. RUSSELL1.
}

\section{(The London School of Hygiene and Tropical Medicine, W.C.1.)}

As Scotland is the only home country for which information is published on the regional distribution of the mortality from cancer according to site, it seemed of interest to examine whether a particular site, or group of sites, had any special geographical location. With this object in view the present investigation was undertaken for the period 1923-8.

The sites of cancer as classified for each county in the Annual Reports of the Registrar General for Scotland are (1) buccal cavity; (2) stomach and liver; (3) peritoneum, intestine, rectum; (4) female genital organs; (5) breast; (6) skin; (7) other organs.

The total deaths only and not the deaths at specified ages were published for these sites. It was assumed, however, that all these deaths occurred after age 35 years. This assumption will introduce a negligible error, since 97 per cent. of the total cancer deaths occur after this age. Since the deaths were not given for specified ages it was necessary to adjust the crude death-rate at ages 35 years and upwards in each county-the deaths at age 35 years and over divided by the corresponding population, so as to eliminate the effects of the differences in the age and the sex constitution of the various populations. This procedure is absolutely essential in dealing with a disease like cancer which mainly affects the higher age periods. The method was that known as "indirect standardisation."

Possessing the requisite data in a suitable form we are now in a position to ascertain the magnitude of the standardised death-rates from cancer of particular sites and also the range of their variability in the counties of Scotland (see Table I). The essential facts are present in Table I in which Col. 1 contains the mean or average standardised death-rate for the particular site, or group of sites, in the counties; Col. 2 indicates the average variability in the mortality rates when the variability of each county is measured from the mean death-rate given in the previous column. Col. 3 enables us to compare the amount of dispersion or scatter in the rates of mortality in the different sites because the values of the standard deviation are expressed as percentages of the corresponding mean death-rates, the formula for the "Coefficient of Variation," in the present instance, being

$$
\frac{\text { Standard deviation }}{\text { Mean death-rate }} \times 100 \text {. }
$$


Table I. Showing the standardised death-rate per 1000 at age 35 years and upwards and the variability of cancer of particular sites in counties of Scotland, 1923-8.

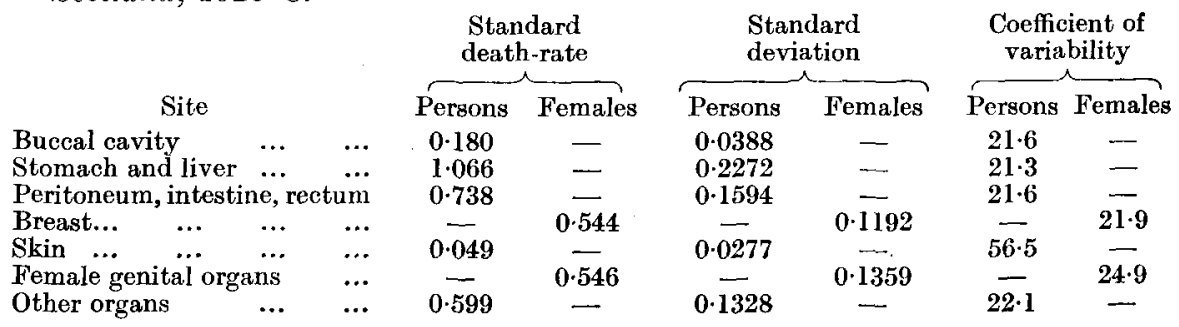

As was to be expected, the greater part of the total mortality from cancer occurs in the group stomach and liver, the death-rate being 1.066 per 1000 , or six times greater than that for the buccal cavity. In the two sites common to women, the genital organs and breast, the rates of mortality are almost equal, being 0.546 per 1000 for the former and 0.544 for the latter. The deathrate from breast cancer, as given in this table, overstates the actual facts to a very small degree, because the deaths as published for each county refer to the males and females combined, but in calculating the death-rate the female population only was used. If the male population had been included in the denominator of the fraction

\section{$\frac{\text { Deaths from breast cancer }}{\text { Population for persons }}$,}

then the prevalence of cancer in this site would have been considerably underestimated. That the inclusion of the male deaths will not be a factor of much importance will be readily understood when it is pointed out that in the whole of Scotland, during the period 1923-8, the male deaths in this site formed less than 1 per cent. of the total number from breast cancer.

When the relative variability of the mortality in different sites is examined it will be observed that it is remarkably constant. The only exception is skin cancer, for which the index is 57 per cent.; the fluctuations in all the other sites lie between 21 per cent. and 25 per cent. No undue importance may be attached to the variation in the mortality from skin cancer, as the amount of cancer in this site is relatively small, being less than 2 per cent. of the total deaths, and the highest standardised death-rate, 0.132 per 1000 in Nairn, was based on a total of four deaths in six years.

We may approach the problem of the geographical distribution of the mortality according to site from another angle by comparing the expected number of total deaths with the actual or observed. The expected deaths in any one county are those which would occur if the male and female population in that county had experienced the rates of mortality for the separate sexes at the various age periods in the whole country. The difference between the actual and expected number of deaths when tested against the standard error 
of the difference will indicate the degree of importance attaching to the amount of cancer of any particular site present in any one county. The standard error of the difference may, for all practical purposes, be regarded as measured by $\sqrt{E}$, where $E$ is the expected number of deaths. Unless the difference exceeds at least twice this criterion it cannot be regarded as of any statistical importance. Applying this test it was found that, for the inaccessible sites of cancer, the recorded number of deaths significantly exceeded the expected in certain counties, but these were mainly counties in which medical skill and the probability of better provision as regards mechanical facilities for diagnosis existed. For instance, in Lanarkshire, containing as it does the city of Glasgow, the actual number of deaths in the group cancer of stomach and liver considerably exceeded the expected; the recorded deaths were 4172, the expected 3419 , a difference of 753 , which is at least twelve times greater than its standard error. The other counties which had an excess of actual

Table II. Showing the distribution of deaths from cancer of the breast in the counties of Scotland, 1923-8.

\begin{tabular}{|c|c|c|c|c|c|c|c|}
\hline \multicolumn{3}{|c|}{ Counties } & Actual & Expected & Diff. & s.t. & S.E. \\
\hline Aberdeen & $\ldots$ & $\ldots$ & 227 & 237 & -10 & $15 \cdot 39$ & 0.65 \\
\hline Argyll & $\ldots$ & $\ldots$ & 56 & 73 & -17 & 8.54 & 1.99 \\
\hline Ayr $\ldots$ & $\ldots$ & $\ldots$ & 206 & 197 & +9 & 14.03 & 0.64 \\
\hline Banff & $\ldots$ & $\ldots$ & 37 & 46 & -9 & $6 \cdot 78$ & 1.33 \\
\hline Berwick & $\ldots$ & $\ldots$ & 32 & 26 & +6 & $5 \cdot 10$ & $1 \cdot 18$ \\
\hline Bute... & $\ldots$ & $\ldots$ & 17 & 32 & -15 & $5 \cdot 66$ & 2.65 \\
\hline Caithness & $\ldots$ & $\ldots$ & 24 & 27 & -3 & $5 \cdot 20$ & 0.58 \\
\hline Clackmann & & $\ldots$ & 21 & 24 & -3 & $4 \cdot 90$ & 0.61 \\
\hline Dumbarton & & $\ldots$ & 95 & 93 & +2 & $9 \cdot 64$ & $0 \cdot 20$ \\
\hline Dumfries & $\ldots$ & $\ldots$ & 60 & 62 & -2 & $7 \cdot 87$ & 0.25 \\
\hline East Lothi & & $\ldots$ & 39 & 34 & +5 & $5 \cdot 83$ & 0.86 \\
\hline Fife $\ldots$ & $\ldots$ & $\ldots$ & 198 & 200 & -2 & $14 \cdot 14$ & 0.14 \\
\hline Forfar & $\ldots$ & $\ldots$ & 222 & 235 & $-1 \overline{3}$ & $15 \cdot 33$ & 0.85 \\
\hline Inverness & $\ldots$ & $\ldots$ & 75 & 81 & -6 & $9 \cdot 00$ & 0.67 \\
\hline Kincardine & $\ldots$ & $\ldots$ & 33 & 32 & +1 & $5 \cdot 66$ & $0 \cdot 18$ \\
\hline Kinross & $\ldots$ & $\ldots$ & 6 & 7 & -1 & $2 \cdot 65$ & $0 \cdot 38$ \\
\hline Kirkcudbri & ght & $\ldots$ & 33 & 33 & 0 & $5 \cdot 74$ & \\
\hline Lanark & $\ldots$ & $\ldots$ & 902 & 875 & +27 & 29.58 & 0.91 \\
\hline Midlothian & $\ldots$ & $\ldots$ & 423 & 392 & +31 & $19 \cdot 80$ & 1.57 \\
\hline Moray & $\ldots$ & $\ldots$ & 36 & 38 & -2 & $6 \cdot 16$ & $0 \cdot 32$ \\
\hline Nairn & $\ldots$ & $\ldots$ & 6 & 9 & -3 & 3.00 & 1.00 \\
\hline Orkney & $\ldots$ & $\ldots$ & 15 & 26 & -11 & $5 \cdot 10$ & $2 \cdot 16$ \\
\hline Peebles & $\ldots$ & $\ldots$ & 6 & 15 & -9 & $3 \cdot 87$ & $2 \cdot 33$ \\
\hline Perth & $\ldots$ & $\ldots$ & 136 & 120 & +16 & 10.95 & 1.46 \\
\hline Renfrew & $\ldots$ & $\ldots$ & 223 & 185 & $\begin{array}{r}+38 \\
+38\end{array}$ & $13 \cdot 60$ & $2 \cdot 79$ \\
\hline Ross and $\mathrm{Cr}$ & romarty & $y \ldots$ & 60 & 70 & -10 & $8 \cdot 37$ & $1 \cdot 19$ \\
\hline Roxburgh & $\ldots$ & $\ldots$ & 55 & 43 & +12 & 6.56 & $1 \cdot 83$ \\
\hline Selkirk & $\ldots$ & $\ldots$ & 21 & 21 & 0 & 4.58 & \\
\hline Shetland & $\ldots$ & $\ldots$ & 18 & 30 & -12 & $5 \cdot 48$ & $2 \cdot 19$ \\
\hline Stirling & $\ldots$ & $\ldots$ & 89 & 98 & -9 & $9 \cdot 89$ & 0.91 \\
\hline Sutherland & $\ldots$ & $\ldots$ & 15 & 19 & -4 & $4 \cdot 36$ & 0.92 \\
\hline West Lothi & & $\ldots$ & 42 & 40 & +2 & $6 \cdot 32$ & $0 \cdot 32$ \\
\hline Wigtown & $\ldots$ & $\ldots$ & 23 & 26 & $-\overline{3}$ & $5 \cdot 10$ & 0.59 \\
\hline
\end{tabular}

deaths as compared with the expected deaths were West Lothian, Midlothian, Renfrew and Forfar, but the disparity was not so well defined as in Lanarkshire. In the Highland counties the position was reversed-the indices were significantly negative, the ratio in Orkney being $-4 \cdot 1$, Shetland $-4 \cdot 5$, 
Inverness $-4 \cdot 2$, Aberdeen $-3 \cdot 9$, Ross and Cromarty $-3 \cdot 9$, Argyll -3.6, and Sutherland $-3 \cdot 6$. It will be observed that the county of Aberdeen lies within the negative eategory, and there is no obvious reason for the deficiency in the amount of cancer of the stomach in that county.

As, with the possible exception of lingual cancer, errors are less likely to occur in the diagnosis of cancer of the breast than in any other site and, as cancer of the buccal cavity can be equally certified in town or country, the distribution of the actual and expected number of deaths occurring in these two sites during the period $1923-8$ are shown for the individual counties in Tables II and III.

Table III. Showing the distribution of deaths from cancer of the buccal cavity in the counties of Scotland, 1923-8.

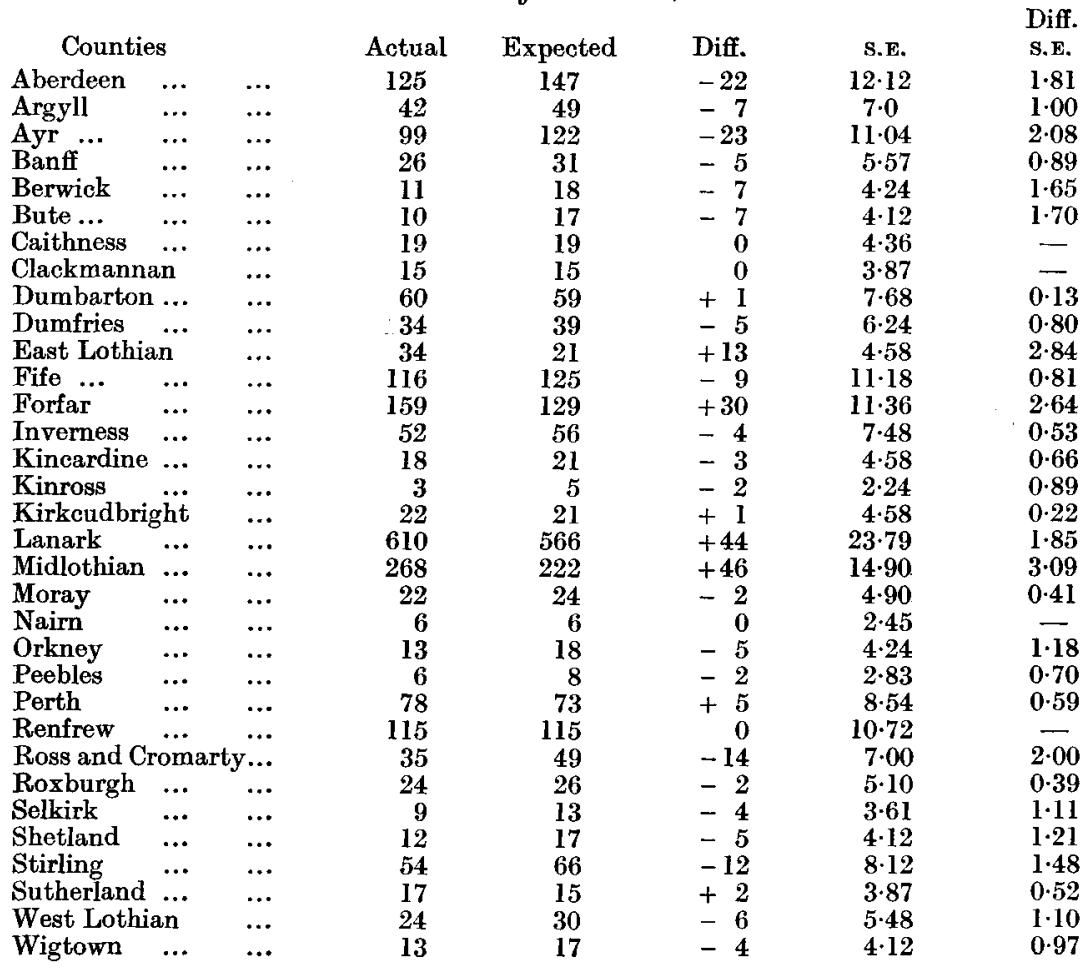

\section{Breast Cancer.}

One would naturally expect to find in the case of mammary cancer the highest mortality in the Highland counties where promptitude of medical attention and facilities for surgical treatment might be expected to be more deficient than in the Lowlands, but there is, as will be seen from Table II, no defined localisation. If anything, the prevailing tendency is towards a deficiency in the amount of breast cancer in the Highlands, but the deficit is not equally marked in the individual counties constituting the group. In 
only one county in Scotland-Renfrew-is the difference between the actual and expected values possibly significant. If the standard errors of the differences were normally distributed we should expect to find that the indices in Col. 5 would be grouped as follows:

$A$. Twenty-three counties showing a difference of less than once the standard error.

$B$. Nine counties showing a difference greater than once but less than twice the standard error.

$C$. One county showing a difference greater than twice but less than three times the standard error.

When the ratios in Col. 5 are assigned to these categories the distribution is 20 in $A, 8$ in $B$ and 5 in $C$. Although there is an apparently large discrepancy between the actual and expected totals, i.e. 5 and 1 respectively in Group $C$, it is not of real importance, as the indices are barely outside the limits of significance, and furthermore, with the exception of the case of Renfrew, they are associated with counties containing relatively small populations.

\section{Cancer of the buccal Cavity.}

As will be observed from the statistics in Table III there is really no specific localisation of the deaths in this site. There is only one countyMidlothian-in which more deaths are enumerated than would be expected on the basis of the mortality rates in the whole country. In all the other counties there is no satisfactory evidence to indicate that the amount of cancer deviates appreciably from the normal standard.

\section{BirTh-RATE AND CANCER AMONGST WOMEN.}

In the Annual Report of the Registrar General for England and Wales for 1913, Dr Stevenson has shown that during the three years 1911-13 the mortality from breast cancer amongst unmarried women was 45 per cent. higher than amongst the married, but as regards uterine cancer the position was almost exactly reversed. It would thus appear that the presence or absence of childbearing is a factor of some importance in influencing the mortality from two forms of cancer amongst women. To what extent are they dependent? For a reliable answer to this question we are indebted mainly to the work of Prof. Greenwood and his colleagues ${ }^{1}$. In his analysis of the data for 39 administrative counties in England and Wales he found that the birthrate during the period 1901-3, based on the number of married women between the ages of 15 and 45 in each county, and the mortality from breast cancer at ages over 25 in the period 1911-20 were correlated to the extent of $-0.514 \pm 0.079$. In other words a low birth-rate was reflected, though not absolutely, in a high mortality from breast cancer. As regards the influence of fertility on the presence of uterine cancer there was little or no relationship, as the coefficient, although negative, was within the error of random sampling.

1 League of Nations. Health Organisation Sub-Committee on Cancer. C.H. 333, 1. 
His results, in the case of the breast cancer and fertility, were confirmed by investigators in two other countries, Italy and Holland, although their conclusions were based on a rather small series of observations.

The position, as regards uterine cancer and fertility in Italy and Holland, particularly in Holland, was quite different from that in England, as, in Holland, the birth-rate was more highly correlated with uterine cancer than with breast cancer. In view of these results it was of interest to examine the degree of relationship exhibited by the Scottish data. For this purpose the birth-rate at each of the two triennial periods, (1) 1900-2 and (2) 1910-12, expressed in terms of the married women 15-45 in the individual counties, was correlated with the standardised mortality rates from breast cancer and uterine cancer respectively during the period 1923-8. The periods 1900-2 and 1910-12 were selected from the fertility standpoint because the majority of the cancer deaths occurring in the two sites during 1923-8 must inevitably have occurred amongst women who were mothers during these two triennia. When the necessary coefficients were calculated it was found (see Table IV)

Table IV. Showing (1) the correlation coefficient between the incidence of cancer of special sites and fertility in the counties of Scotland, (2) similar results for other countries.

(1) Scotrand. Standardised death-rate at age 35 years and upwards for the period 1923-8.

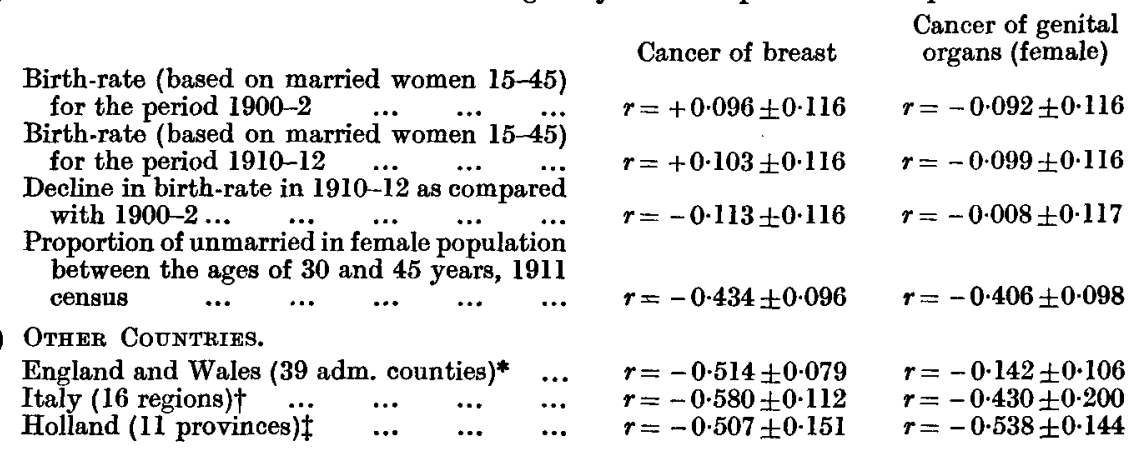

* Mean birth-rate 1901-3 per 1000 married women ages 15-45 and cancer 1911-20 ages 25 and over.

$\dagger$ Cancer mortality all ages over 20, 1919-21. Legitimate births 1919-21 in terms of married women 15-45 (June, 1911).

$\ddagger$ Mean birth-rate $1900-4$ per 1000 married women under 50 and cancer 1913-22 all ages.

that there was no relationship between the amount of breast cancer and the previous size of the birth-rate. The values obtained were positive, as compared with the negative coefficients found in the other countries, but they were statistically unimportant. A further test was applied. The mortality from breast cancer was correlated with (1) the decline in the birth-rate in each county between 1900-2 and 1910-12, but no direct or indirect relationship was found to exist; (2) with the proportion of single women in the female population between the ages of 30 and 45 years in each county at the 1911 census. The age limits $30-45$ years were selected on the assumption that the 
unmarried population in this age group contributed largely to the number of spinsters exposed to risk of cancer in later life. The coefficient of correlation in this instance was $-0 \cdot 434 \pm 0 \cdot 096$. This result, although contrary to expectation, was confirmed when the mortality from breast cancer was correlated with the proportion of single women aged 45 years and upwards in the total female population at this period of life at the 1921 census. The coefficient was $-0 \cdot 404 \pm 0 \cdot 096$. In view of the higher mortality from breast cancer amongst unmarried than married women as recorded by Dr Stevenson in England and Wales one would have expected a positive and not a negative answer. The coefficients were also evaluated between uterine cancer and the same factors, but no tangible relationship was demonstrated except in one instance-the proportion of unmarried was significantly correlated in a negative direction with the mortality from uterine cancer. If the absence of childbearing (as measured by the proportion of unmarried in the population) is reflected in a diminution of uterine cancer as the figures for Scotland seem to suggest, then it would appear logical to assume that the impairment of the physiological functioning which often occurs at birth would find expression in a positive association between uterine cancer and fertility. The correlation coefficients between the two variables as found in each of the four countries lend no support to this deduction.

From this survey of the distribution of the mortality from cancer according to site in the counties of Scotland during the six years 1923-8, the following is a fair representation of the facts.

Conclusions.

1. With the exception of skin cancer the relative variability of the mortality in the other sites, or group of sites, is remarkably constant in Scotland as the coefficients of variation fall within a range of 21 to 25 per cent. (see Table I).

2. The counties possessing the best equipped hospitals have a greater amount of inaccessible cancer than might be expected to occur. In Lanarkshire, for example, the actual deaths from cancer of the stomach and liver numbered 4172 , the expected $3419-$ a difference of 753 , which is approximately thirteen times greater than its standard error.

3. As regards the two accessible sites-breast and buccal cavity-there is no defined localisation in the mortality, as the number of deaths in each county, with possibly two exceptions, Renfrew for breast cancer, Midlothian for buccal cavity, approximately follow a normal distribution.

4. There is no evidence that the decline in the Scottish birth-rate in the individual counties has had any influence in the incidence of either breast or uterine cancer, as the coefficients of correlation were statistically insignificant.

(MS. received for publication 30. Iv. 1931.--Ed.) 